\title{
Midia-educação e pesquisa educativa
}

\section{Pier Cesare Rivoltella*}

\section{Resumo:}

Este texto se propõe a definir a especificidade da pesquisa no âmbito da Mídia Educação em relação à pesquisa educativa. Para tal, parte da moldura epistemológica apresentada por Van der Maren (2003) contextualizando-a no interior da pesquisa internacional sobre a relação entre mídia e educação.

Palavras-chave: Mídia. Pesquisa educacional. Epistemologia. Educação - Meios auxiliares.

* Professore Ordinario di Didattica e Tecnologie dell'educazione da Università Cattolica del Sacro Cuore (UCSC), Sedi Milano. Presidente da SIREM (Società Italiana di Ricerca sull'Educazione Mediale). 
Nesta contribuição pretendemos alcançar dois objetivos: destacar a diferença entre a pesquisa em Mídia Educação e a pesquisa educativa desenvolvida em torno das mídias. No contexto internacional há os que consideram que a Mídia Educação não possua especificidade de pesquisa e deva ser compreendida nos interesses mais gerais da pesquisa pedagógica (assim como existe uma pedagogia do meio ambiente, dos adultos etc., existiria também uma pedagogia dos meios ou uma pedagogia das mídias). ${ }^{1}$ A nossa ideia é diferente. Pretendemos demonstrá-la definindo o espaço exato dos dois âmbitos, procedendo a um trabalho de cartografia cognitiva de uma e de outra.

\section{Pesquisa educativa sobre as mídias, pesquisa em Mídia Educação}

A narratologia - e em consequência, a pragmática textual - tem elaborado categorias operativas para definir o posicionamento do narrador (daquele que fala ou detém a comunicação) a respeito da narrativa que vai se desenvolvendo (CASETTI; DI CHIO, 1990). Trata-se dos conceitos de ponto de vista e de focalização.

O conceito de ponto de vista define a narração no seu caráter interno a respeito da narrativa. Posso narrar uma história contemporânea ao meu tempo (ponto de vista homodiegético) ou da qual faço parte diretamente (ponto de vista intradiegético), mas também uma história que pertence a um tempo diferente do meu (ponto de vista heterodiegético) ou da qual não fiz parte (ponto de vista extradiegético). A dialética, neste caso, é de dentro-fora: descrever algo do ponto de vista exterior ou interior.

Diferente é o caso da focalização que, ao contrário, indica a relação existente entre o narrador e os personagens de sua narração. Assim, há focalização interna quando a voz do narrador se exprime pela boca dos personagens, como no discurso direto ou no fluxo de consciência joiceano; a focalização é externa quando o eu narrador não se identifica com nenhum dos personagens, mas narra os fatos do exterior, de fora, poderíamos quase dizer "do alto" (é o caso do romance histórico oitocentista). A diferente deslocalização do eu narrador pretende definir o objeto da narração, demarcar os limites, configurando caso a caso como narração autobiográfica, crônica, reconstrução histórica. A dialética de dentro-fora é substituída por 
uma nova dialética de identidade-diferença: descrever algo enquanto acontece, descrever algo sem ser por isso ator do que está acontecendo.

No caso da relação entre a pesquisa em Mídia Educação e a pesquisa educativa sobre as mídias o problema pode ser analisado através destas duas categorias: é um problema de ponto de vista e de focalização. O objetivo é o de distinguir, no interior da pesquisa educativa sobre os meios, um sub-campo de investigação de elevado perfil específico - o da Mídia Educação - que convém individualizar segundo características que o tornam irreduzível a outros. A distinção entre pesquisa educativa sobre as mídias e pesquisa no âmbito da Mídia Educação, que buscaremos definir, não é pensada como uma diferença entre conjuntos diversos, mas entre um sub-conjunto (a pesquisa em Mídia Educação) e o resto do conjunto a que ela pertence (a pesquisa educativa sobre as mídias).

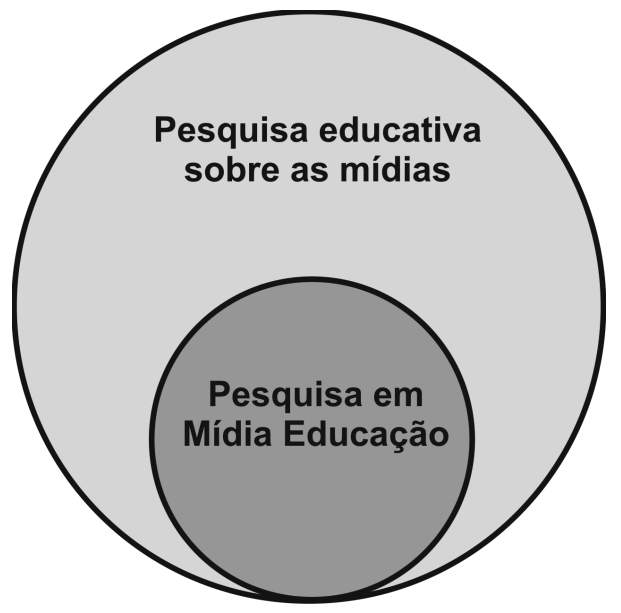

Figura 1 - Mídia, pesquisa educativa, mídia educação

\section{A pesquisa educativa: objeto, discurso, agenda}

A pesquisa, também no âmbito educativo, se define sempre em relação a três elementos fundamentais: um objeto, sobre o qual se faz pesquisa (plano ontológico); um discurso, que implica um posicionamento teórico e as escolhas de método correspondentes (plano metodológico); uma agenda, no sentido dos resultados que a pesquisa pretende alcançar em relação a um determinado contexto (plano funcional). 


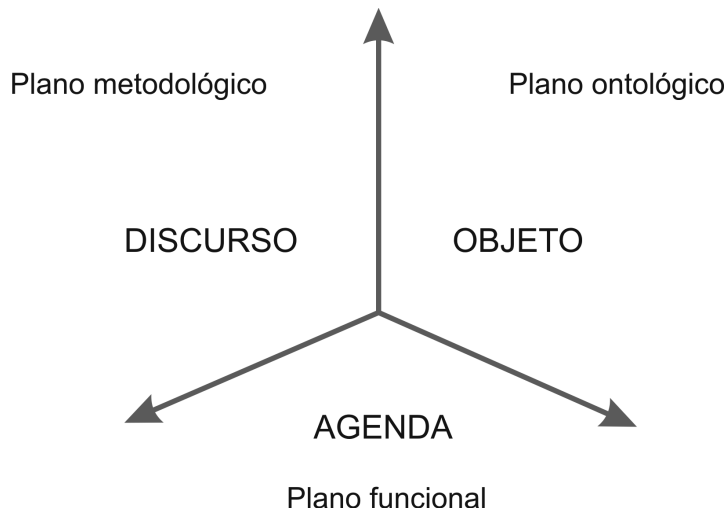

Figura 2 - Elementos e planos da pesquisa

Para cada um destes planos e elementos é possível introduzir descritores que facilitam o reconhecimento e a operacionalização no interior da pesquisa materialmente conduzida. Dois destes descritores são justamente aqueles do ponto de vista e da focalização. O ponto de vista diz respeito ao plano metodológico e serve para a definição do tipo de discurso que é elaborado através da pesquisa no que se refere a um determinado argumento. Segundo o modelo de Van der Maren (2003), é possível individualizar quatro tipologias de discursos:

- a descrição, que "se limita a identificar os elementos e suas relações estáticas, a delimitar o objeto da pesquisa e classificar seus componentes, a definir o estado da situação" (VAN DER MAREN, 2003, p. 34);

- a compreensão, que "especifica as implicações entre os diversos elementos, a sua dinâmica. A causalidade é local e restrita. Tratase de considerar a correlação entre os elementos de uma situação: sua origem e a sequência de eventos que conduziram a ela" (VAN DER MAREN, 2003, p. 35);

- a explicação, é a "evidência das regularidades, das regras, dos princípios que se manifestam no tempo e no espaço, entre ocorrências similares ou do mesmo gênero" (VAN DER MAREN, 2003, p. 35);

- a formalização, que constitui o nível mais abstrato de elaboração e consiste na teorização geral dos princípios e regras válidas para todos os fenômenos do mesmo tipo. 
Para cada um destes quatro tipos de discurso é possível individualizar um ponto de vista específico: tendencialmente interno é aquele descritivo e compreendente; externo é aquele explicativo e formalizante. A focalização é relativa ao plano ontológico e favorece a delimitação do objeto sobre o qual a pesquisa acontece. Seguindo a indicação de Jacquinot (2002, p. 2022) é possível reconhecer no interior da pesquisa educativa em torno das mídias as seguintes áreas de interesse:

- a análise das práticas midiáticas, ou seja, das atividades de leitura que vêem as crianças como protagonistas (o que lêem? Quando? Quanto? Em que proporção entre os diversos meios? Com quais transformações no tempo?);

- o estudo das representações das mídias, ou seja, das formas através das quais as mídias se ocupam da família, do gênero (masculino/feminino), da relação adulto-crianças, das minorias. Pertencem a esta área de pesquisa os estudos sobre socialização, sobre efeitos da violência ficcional sobre comportamentos agressivos do público, sobre funções dos estereótipos midiáticos na estruturação dos quadros de valores e comportamentos das crianças e adolescentes;

- o estudo da pesquisa em contexto, ou seja, a área de pesquisa que, reconduzindo o consumo de mídias ao fenômeno mais geral da formação das culturas juvenis, permitiram equilibrar as hipóteses excessivamente alarmistas que, deterministicamente, acreditam que as mídias produzam inevitavelmente efeitos devastadores no público de crianças e adolescentes;

- o estudo do funcionamento das mídias, vale dizer a análise das dimensões econômico-política e semio-pragmáticas das mensagens.

Se pode estudar a influência da desregulamentação das telecomunicações sobre conteúdos da mídia, a comercialização das mídias através do mercado e o uso da criança como consumidora, como fonte de informação e como álibi para promover uma auto-regulamentação da indústria da mídia; e em consequência, se lamentará a adoção de soluções técnicas de regularização ( $V$-Chip, sistema de filtro 
para Internet) em detrimento de uma política de responsabilização dos produtores e dos emissores. (JACQUINOT, 2002, p. 21).

Sobre a outra vertente, ao contrário - aquela da análise semio-pragmática -, a atenção é ao processo de produção de sentido, às práticas colocadas em jogo pelo espectador para ler criticamente as mensagens, à negociação de significados que o texto promove envolvendo o espectador através de estratégias e táticas de posicionamento do seu olhar e do surgimento dos seus movimentos interpretativos. A respeito desta área de pesquisa, a categoria da focalização permite verificar limites e pertinências da investigação evidenciando ora a centralidade das mídias ora do agir educativo.

Resta definir o plano funcional que, como vimos, fornece a própria agenda à pesquisa. Sempre seguindo Van der Maren (2003) é possível distinguir pelo menos três finalidades que a pesquisa educativa pode ter:

- a finalidade pedagógica, caracterizada pela intenção de alcançar uma melhor compreensão do homem e seu ambiente. Trata-se da finalidade da pesquisa educativa mais ligada ao ensino e à formação e às suas modalidades em vista da possibilidade de obter um resultado formativo mais eficaz;

- a finalidade epistemológica, que toma corpo nas investigações sobre o estatuto das disciplinas e sua fundamentação teórica. Em relação à finalidade pedagógica, ela possui em primeiro plano a força crítica da reflexão e é endereçada à discussão de soluções teóricas já individualizadas com o objetivo de alimentar a dúvida a respeito do seu método e da sua prática de investigação;

- a finalidade técnica, nas suas duas variantes:

- pragmática, quando a pesquisa se propõe a produzir artefatos que permitem controlar o ambiente físico (desenvolvimento de pesquisas no âmbito de tecnologias didáticas e de e-learning) ou de responder a determinadas necessidades (produção de materiais didáticos);

- política, quando o objetivo não é alcançar a produção de alguma coisa, mas o desenvolvimento de serviços colocados à 
disposição dos indivíduos ou dos grupos (a pesquisa sobre o sistema integrado escola-território é típica desta orientação).

Se quisermos encontrar, como nos outros casos, um descritor também para este terceiro plano com os seus elementos é possível individualizá-lo na orientação funcional da pesquisa: se a focalização consiste em responder a pergunta: "Do que se ocupa a pesquisa?" e o ponto de vista à pergunta: "Com que método?", a orientação funcional coloca outra, não menos importante, interrogação: “Com que objetivos?”.

Tabela 1 - A pesquisa educativa: formas e métodos

\begin{tabular}{c|c|c|c}
\hline $\begin{array}{c}\text { Plano de } \\
\text { pesquisa }\end{array}$ & Componente & Descritor & Problema \\
\hline Ontológico & Objeto & Focalização & $\begin{array}{c}\text { De que se ocupa a } \\
\text { pesquisa? }\end{array}$ \\
\hline Metodológico & Discurso & Ponto de vista & Com que método? \\
\hline Funcional & Agenda & $\begin{array}{c}\text { Orientação } \\
\text { funcional }\end{array}$ & Com quais objetivos? \\
\hline
\end{tabular}

\section{A pesquisa em Mídia Educação: especificidade}

Os três descritores que individualizamos (focalização, ponto de vista, orientação funcional) podem nos guiar na tarefa de individualizar qual seja a especificidade da pesquisa no âmbito da Mídia Educação no interior do contexto mais amplo da pesquisa educativa em torno das mídias.

A pesquisa educativa sobre as mídias se organiza em torno das quatro áreas que vimos acima fazendo referência às indicações de Jacquinot (2002). Em primeiro lugar, ela trabalha sobre a relação entre as mídias e a organização dos conhecimentos do fruidor. Enquadram-se aqui todas as pesquisas sobre a capacidade de as mídias facilitarem e sustentarem a aprendizagem. Podemos pensar nas contribuições do comportamentalismo (mídia como instrumento), do cognitivismo (mídia como sistemas simbólicos que interagem com a mente), do construtivismo (mídia como espaço de negociação de significados) (MESSINA, 2002; VARISCO, 2003).

Uma segunda área de pesquisa significativa está relacionada ao sistema de representação que as mídias continuamente organizam. Este sentido é muito bem interpretado por Roger Silverstone (1999, p. 127): 
Segundo o meu ponto de vista é necessário estudar as mídias porque elas são da máxima importância para a experiência, dando-lhe forma. Sustentei que este estudo deve envolver uma concepção das mídias não como uma série de instituições, produtos ou tecnologias (pelo menos não só deste modo), mas também como um processo de mediação. As mídias são produzidas: e neste produzir nós somos os agentes e destinatários.

Trata-se de um tema importantíssimo no âmbito da pesquisa educativa na medida em que estas representações constituem um dos territórios privilegiados da educação informal (a teorização das mídias como "escola paralela" deriva deste gênero de investigação que, sobretudo na década passada, forneceu importantes confirmações às hipóteses illichianas da desescolarização).

Também devem ser considerados os estudos que se ocupam do sistema de relações que ligam as mídias com a audiência e os contextos sociais em que são inseridos. A palavra-chave neste olhar é socialização. Metodologicamente, a pesquisa que trabalha em torno destes temas depende, como fundamentação, da abordagem dos Estudos Culturais

e se preocupa em compreender a "cultura vivida" no cotidiano, no interior de grupos sociais específicos. [...] A ênfase é colocada aqui sobre as diferentes implicações entre o uso das mídias e as atividades sociais, ou o contexto relacional. [...] As mídias não são consideradas simplesmente como um meio para transmitir "mensagens" sobre um público passivo; o interesse não é mais simplesmente sobre o encontro isolado do espírito e da tela. Ao contrário, este tipo de pesquisa considera os usos das crianças e a interpretação das mídias como processos intrinsecamente sociais; e ela os compreende como processos caracterizados por formas de poder e de diferença. Nesta perspectiva, o que significa ser criança não é algo fixo ou dado, mas algo socialmente construído e elaborado. (BUCKINGHAM, 2002, p. 110). 
A observação participante e os métodos etnográficos em geral tornamse o instrumento obrigatório para sustentar esse tipo de investigação. ${ }^{2}$

Temos enfim os aportes da pesquisa que refletem em termos educativos sobre estrutura e funções dos produtos midiáticos com a clara intenção de colocar à disposição de quem desenvolve atividades formativas, métodos e técnicas para abordar os alfabetos das mídias (um tema muito frequente a partir dos anos setenta quando se começou a pensar nas linguagens das mídias como implicações do desenvolvimento dos "novos alfabetos"). Inscrevem-se nesta área de interesse tanto as pesquisas caracterizadas pela análise educativa dos produtos educacionais ${ }^{3}$ quanto àquelas que enfatizam estratégias de leitura educativa eficazes para as diversas tipologias dos produtos midiáticos. ${ }^{4}$

A pesquisa própria da Mídia Educação - a prescindir da questão epistemológica de sua definição enquanto campo disciplinar que foi seguramente a primeira a ser examinada - evidencia, sobretudo, a dimensão política e operativa. O problema principal é como fundamentar o trabalho educativo (em relação às novas mídias, à globalização etc.) e como agir sobre as políticas públicas do Estado, responsáveis pela educação das novas gerações, no sentido de uma significativa e livre relação com as mensagens das mídias? Em síntese, parece ser possível dizer que enquanto a pesquisa educativa sobre as midias em geral é centrada sobre as mídias nas suas implicações educativas (abordagem media centred), a pesquisa no âmbito da Mídia Educação é, ao contrário, decisivamente empenhada em tornar possivel um agirpolítico e educativo eficaz. em relação às mídias (abordagem education centred).

Ainda sobre a ordem do ponto de vista, a especificidade da pesquisa em Mídia Educação a respeito do âmbito geral da pesquisa educativa sobre as mídias é evidente. O ponto de vista da pesquisa educativa sobre as midias em geral é externo a respeito dos fenômenos estudados; o pesquisador não é necessariamente também um educador (embora não se possa excluir formas de pesquisa educativa em que o pesquisador seja um educador) e, no entanto, a sua reflexão sobre o objeto da própria pesquisa não co-envolve as suas práxis educativas e didáticas. Diferentemente, o ponto de vista da pesquisa no âmbito da Mídia Educação é sempre interno; isto significa que o pesquisador é quase sempre um educador que se serve da pesquisa para melhorar a eficácia ${ }^{5}$ de sua intervenção ou para pressionar as organizações (como a escola) 
ou as instituições para adotar a Mídia Educação como um quadro de referências para a ação educativa a respeito das mídias.

Esta última dupla referência à melhoria da eficácia da intervenção educativa e para a ação de pressionar as instituições permite introduzir o último descritor que individualizamos, aquele relativo à orientação funcional da pesquisa. A pesquisa educativa investiga sobre a realidade das midias deixando-se guiar pela hipótese, mas sem possuir respostas de antemão: a sua orientação é decisivamente cognoscitiva (entender como funcionam as representações das mídias em relação às aprendizagens, como as crianças reagem diante da violência ficcional, se a propaganda televisiva modifica as intenções configurando-se como uma pedagogia do consenso). A pesquisa no âmbito da Mídia Educação, ao contrário, possui respostas de antemão (que encontra na pesquisa educativa sobre as mídias), portanto, já sabe que existe uma relação entre representação das mídias e aprendizagem, quais podem ser as reações das crianças diante da violência ficcional etc. A partir disso formula questões que podem ajudar os sujeitos a prestar atenção de maneira crítica e autônoma no que diz respeito aos programas transmitidos pelas mídias: a orientação funcional não é a de conhecer alguma coisa, mas de produzir efeitos. Trata-se de uma orientação pragmática, ou melhor, mais especificamente pedagógica (no sentido etimológico do agir educativo).

Tabela 2 - Pesquisa educativa sobre as mídias e pesquisa em Mídia Educação

\begin{tabular}{c|c|c}
\hline & $\begin{array}{c}\text { Pesquisa educativa sobre as } \\
\text { mídias }\end{array}$ & $\begin{array}{c}\text { Pesquisa em Mídia } \\
\text { Educação }\end{array}$ \\
\hline Focalização & Media centred & Education centred \\
\hline Ponto de vista & Exterior & Interior \\
\hline Orientação funcional & Cognoscitiva & Pragmática \\
\hline
\end{tabular}

\section{Cuidados}

Sobre a demarcação dos campos de pesquisa da Mídia Educação e da pesquisa educativa sobre as mídias é importante destacar duas considerações a respeito de como os termos foram conduzidos. 
- Antes de tudo, destacar que cada esquematização nunca é perfeita: ela sempre corre o risco de engessar a realidade na simplicidade do esquema. Referimos-nos à Tabela 2 em que a dupla instância (modelo rígido + simplificação) é evidente.

Dizer que a pesquisa educativa sobre as mídias é media centred não significa, evidentemente, sustentar que ela se desinteressa pelas questões educativas: seria contraditório a respeito de sua própria natureza de pesquisa "educativa". A afirmação deve ser entendida no sentido relativo, isto é, relacionada à focalização da pesquisa que é própria da Mídia Educação e que, em relação a ela, é decisivamente mais centrada sobre os processos educativos (embora isto não signifique sustentar que por isso não se ocupe das mídias). Se, em síntese, a relação mídia-educação pode ser lida em duas direções - o que implicam as mídias para a educação e o que faz a educação às mídias - pode-se dizer que o percurso que conduz da mídia à educação é o espaço precípuo da pesquisa educativa, enquanto que aquele da educação às mídias é o da Mídia Educação. E o percurso que conduz das mídias à educação é o espaço precípuo da pesquisa educativa, enquanto que o percurso da educação às mídias é o espaço da Mídia Educação.

A consciência desta diferença é importante para não correr o risco de confundir os âmbitos de pesquisa conservando em cada um uma especificidade de método e finalidade. Frequentemente, acontece de se acreditar fažer pesquisa em Mídia Educação quando na verdade se está fazendo pesquisa educativa sobre as mídias ou, ainda mais, se está fazendo pesquisa sobre as mídias e só.

A orientação das ciências humanas e sociais (particularmente da Sociologia e da História) tem se voltado nos últimos anos às experiências individuais e sociais dos indivíduos. ${ }^{6}$ Como sugere Silverstone (1999, p. 19)

devemos estudar as mídias segundo os termos de Isaiah Berlin, como parte da "textura geral da experiência", fazendo referência à natureza da vida radicada na vida do mundo, àqueles aspectos da experiência que tratamos como corriqueiros mas que são indispensáveis à vida social e à comunicação.

Isto significa que nas ações que vêem os grupos e os indivíduos como protagonistas também haja a dimensão do educar: 
Trata-se, portanto, de examinar as mídias como processo, como agentes e como objetos dados, em todos os níveis, em qualquer lugar em que os seres humanos se agregam no espaço real ou virtual, onde se comunicam, procuram persuadir, informar, divertir, educar; onde procuram, com uma multiplicidade de formas e com diferentes graus de sucesso, se conectar uns com os outros. (SILVERSTONE, 1999, p. 21).

No entanto, muitas pesquisas no campo da sociologia e da psicologia, recentemente feitas no sentido desta abordagem, consideram seus resultados ligados à Mídia Educação quando na verdade nem mesmo são pesquisas educativas. É muito diferente:

- ocupar-se da educação como uma das atividades humanas interessadas pela mediação das mídias;

- estudar as implicações educativas das mídias;

- individualizar métodos e técnicas eficazes para fazer intervenções educativas com e sobre as mídias.

O educar está no centro da atenção de todos os três tipos de atividade de pesquisa, mas: no primeiro caso (pesquisa sobre as mídias) como atividade humana entre as outras - a agregação, o comunicar, o divertir-se, o persuadir etc., como sugere Silverstone (1999); no segundo caso (pesquisa educativa sobre as mídias) a atenção é ao co-envolvimento e aos estímulos das mídias em matéria de educação, em síntese "ao que as mídias fazem à educação"; no terceiro caso, enfim (a pesquisa na Mídia Educação), apresenta uma atenção direta nas escolhas que o educador pode fazer para intervir educativamente na relação que as mídias instauram com os sujeitos (sobretudo em idade evolutiva).

- O cenário epistemológico atual sugere a necessidade de integrar os saberes e de contaminar as abordagens para ir ao encontro da natureza complexa da realidade. Neste sentido, a categoria complexidade serve para definir "tanto a sociedade quanto os saberes": a sociedade, na medida em que a realidade articulase em vários subsistemas e cada objeto em seu interior não se deixa compreender se não por meio de um jogo de relações e de reenvios a outros objetos; os saberes, uma vez que nesta rede de 
relações requerem uma abordagem disciplinar híbrida, transversal, configurando a complexidade "como um paradigma epistêmico geral, como ideal operativo-regulativo e descritivo de saberes contemporâneos." (PESARE, 2002, p. 35).

A transversalidade disciplinar e a forte ancoragem a contextos de vida articulados contra-distinguem, do ponto de vista epistemológico, também a Mídia Educação. Neste sentido, Jacquinot (2000, p. 4) retoma a reflexão de Armand e Michele Mattellart, sobre a natureza híbrida, várias vezes sublinhada, situando-a como “objeto-fronteira” próprio para indicar a transversalidade a respeito de domínios de saber diferentes: a especificidade de disciplinas como estas, sublinha a estudiosa francesa, está no fato de que 'se interessam por um 'objeto' novo e que se trata de disciplinas menos 'obedientes' que outras a uma tradição paralisante” e, sobretudo, como bem evidenciou Mattellart (apud JACQUINOT, 2000, p. 4), "menos pretensiosas que outras em dar respostas a perguntas mal colocadas." Compartilha desta abordagem também a nossa escolha de definição de Mídia Educação (RIVOLTELLA, 2001) que consiste em entender que ela, mais que uma teoria de campo no âmbito das ciências da educação ou das ciências da comunicação, é um campo de teorias (e de práticas) que entrecruza as duas. ${ }^{7}$ Esta transversalidade significa que quem se ocupa de Mídia Educação, seja educador ou pesquisador, conheça e utilize de instrumentação conceitual e metodológica tanto das ciências da educação quanto da ciência da comunicação. No entanto, isso não quer dizer que quem faz Mídia Educação não deve se ocupar de pesquisa sobre as mídias ou de pesquisa educativa sobre as mídias: se trata de metodologias e de técnicas que devem estar presentes em sua "caixa de ferramentas"; como vimos, a pesquisa da Mídia Educação é parte integrante da pesquisa educativa sobre as mídias. O importante é que se tenha consciência da especificidade de cada abordagem para não comprimir uma na outra.

\section{Espaços de pesquisa na mídia educação}

Se nas ciências da educação reconhecemos um componente fundante (a filosofia da educação como discurso geral sobre o homem e seus valores), um componente interpretativo (a natureza do fato educativo, a pedagogia geral) e um componente metodológico (a didática e a experimentação como 
saber operativo, prático e projetual) não será difícil individualizar nesta última dimensão o espaço mais adequado à Mídia Educação. Mais uma vez, isso não significa que a Mídia Educação não viva também de uma dimensão fundante e interpretativa - que, pelo contrário, descreve interessantes contribuições: simplesmente ela encontra a própria especificidade na práxis e na projetualidade educativa, portanto, na didática. Jean-Marie Van der Maren, cuja contribuição referimos, sugere adotar quatro articulações-chave como critério para descrever os diferentes âmbitos da pesquisa em educação.

- nomotético: define uma pesquisa dirigida à produção de um saber ordenado a respeito dos fenômenos estudados;

- pragmático: a pesquisa assim caracterizada é orientada à solução de problemas funcionais;

- político: designa uma pesquisa que pretende produzir mudanças nos indivíduos ou nas instituições;

- ontogenético: além da pesquisa como forma de autoconhecimento, visa à melhoria de si.

Esta matriz de quatro descritores é preferível àquela tradicional que distingue pesquisa fundamental e aplicada:

- primeiramente porque a inclui. A pesquisa fundamental, de fato, designa o âmbito da pesquisa nomotética e corresponde àquela que no sentido restrito é definida como pesquisa em âmbito educativo. A pesquisa aplicada, ao invés, envolve a área de interesse das outras três articulações com aquela que é melhor definir como pesquisa pedagógica;

- em segundo lugar, porque, transferindo a atenção do tipo de racionalidade colocada no campo da pesquisa (fundamental/ aplicada) ao propósito em questão (introduzir regularidades, resolver problemas, produzir mudanças em nível individual e coletivo), permite uma melhor avaliação dos diferentes tipos de pesquisa.

Operativamente, cada um das quatro articulações desenha ações que são específicas da pesquisa aplicada:

- a ação específica da articulação nomotética é o prescrever, ou seja, "o proclamar leis, princípios gerais, teorias"; 
- cada uma das outras articulações, ao invés, é descrita por três ações fundamentais que são o observar e avaliar (produzir avaliação de produtos e/ou de processos), o agir (produzir qualquer forma de intervenção) e o construir (encaminhar um processo de desenvolvimento).

Enquanto a pesquisa nomotética é funcional para adquirir novos conhecimentos, as outras três formas da pesquisa aplicada tendem a realizar e sustentar instrumentalmente a ação.

Tabela 3 - As articulações da pesquisa educativa

\begin{tabular}{c|c|c|c}
\hline \multirow{2}{*}{ Articulação } & $\begin{array}{c}\text { Tipo de } \\
\text { pesquisa }\end{array}$ & Ações & Objetivos \\
\cline { 1 - 2 } Nomotética & Fudamental & Prescrever & Conhecer \\
\cline { 1 - 1 } Pragmática & & Justificar \\
\cline { 1 - 1 } Política & \multirow{2}{*}{ Aplicada } & Agservar e avaliar & Realizar \\
\cline { 1 - 1 } Ontogenética & & Construir & $\begin{array}{c}\text { Sustentar } \\
\text { instrumentalmente }\end{array}$ \\
\hline
\end{tabular}

No caso da Mídia Educação todas as quatro articulações são usadas, mas não todas as formas de pesquisa. A monitoração da pesquisa produzida nas décadas de oitenta e noventa até hoje permitem registrar:

- no âmbito da pesquisa nomotética, uma clara preponderância da pesquisa teórica e no âmbito da pesquisa empírica o privilégio da estratégia monográfica típica do estudo de caso, mais que a estatística;

- a pesquisa pragmática está mais orientada à produção de objetos;

- a pesquisa política possui grande destaque (provavelmente a mais frequente), tanto na pesquisa-ação como na produção de conceitos;

- há também a presença de pesquisa fundamentada segundo o modelo de pesquisa avaliativa com objetivo justificativo, ou seja, 
a pesquisa que pretende avaliar para justificar um estado de coisas existente.

A importância da pesquisa teórica se explica, muito provavelmente, com base em duas ordens de razão. Primeiramente, a Mídia Educação foi desenvolvida como movimento, como sensibilidade, como um conjunto de entusiasmos e isto fez surgir, a certo ponto, a exigência de um discernimento e de um reconhecimento que permitisse estabelecer a identidade, individualizar as especificidades de intervenção, reorganizar as práticas metodológicas. A este motivo se agrega o fato de que ela representa um tipo de trabalho educativo que cada vez mais se torna uma necessidade social no interior de um modelo de sociedade que, como a nossa, se pode definir como learning society devido ao papel decisivo que os meios e as novas tecnologias da informação desempenham em relação à circulação de significados e à organização e arquivação de saberes. A estas necessidades sociais não corresponde, todavia, um explícito reconhecimento da Mídia Educação, seja ao nível profissional ou institucional: percebe-se a exigência, mas não se consegue ainda definir a identidade e os espaços ocupacionais.

O duplo debate, em grande parte ainda em curso, sobre o estatuto da Mídia Educação (é ou não é uma disciplina? Como se coloca a respeito das ciências da educação e da comunicação?) e sobre a figura do mídia-educador justifica a pesquisa de uma resposta a ambas as questões.

A impressão - que, porém, deve ser verificada - é que no contexto europeu (visivelmente na Itália, país em que provavelmente a definição epistemológica do objeto Mídia Educação viveu o seu nível de elaboração mais sofisticado) foi adotada, majoritariamente, a preferência pelo caminho da análise crítica enquanto no continente norte-americano prevalece a orientação ao estudo de caso.

Por outro lado, uma tendência constante da pesquisa no âmbito da Mídia Educação, seja no contexto europeu ou no americano é a produção de objetos. A referência é, neste caso, tanto à criação de materiais didáticos (cadernos operativos, subsídios audiovisuais, pacotes multimídias off e on-line) como às atividades de produção de mídia na didática. Trata-se de uma área de pesquisa extremamente interessante e da qual é difícil ter um mapeamento. Essa área diz respeito às micropráticas didáticas dos 
professores e educadores que devem considerar o saber tácito de muitos operadores, aspecto que torna ainda mais difícil a documentação: de um lado, porque na maioria das vezes falta uma reflexão teórica sobre o trabalho que se está fazendo, sendo este o resultado de habilidades operativas adquiridas "sobre o campo" ao longo dos anos; de outro lado, porque grande parte destas atividades de pesquisa, movendo-se na área da Mídia Educação, não tem consciência de si e por isso não se consegue nem mesmo algum tipo de impacto sobre o posicionamento das organizações em que são desenvolvidas (escola, comunidade etc.).

Esta consciência não falta à pesquisa política, seja de intervenção ou de desenvolvimento. A pesquisa-ação e o desenvolvimento de conceitos são suas duas formas principais (e as mais frequentes). Mais uma vez as motivações podem ser buscadas na natureza da própria Mídia Educação: se antes, para justificar a atenção da pesquisa para a reflexão teórica, se sublinhava o caráter "movimentista", aqui é o caso de fazer referências à sua prerrogativa de interligar-se com as instâncias da democracia e da cidadania. Trabalhando para a criação do pensamento crítico contra os riscos de homologação produzida pelas mídias, a Mídia Educação frequentemente assumiu, e ainda hoje assume, posturas que vão do pronunciamento em defesa do usuário (as “cartas" dos direitos são um dos instrumentos clássicos em relação a isso) à pressão sobre as instituições para fazer escolhas eficazes em torno da regulamentação das atividades dos produtores ou o espaço de atividades de educação para as mídias nos programas escolares.

Uma lógica similar se verifica também na parte da pesquisa em Mídia Educação que se ocupa da avaliação. Não por acaso a tipologia de pesquisa mais frequente em tal direção é a representada pela pesquisa com objetivo justificativo, ou seja, por um tipo de pesquisa em que o objetivo é demonstrar a oportunidade e a eficácia da intervenção da Mídia Educação: como sabemos, tal tipo de abordagem se expressa habitualmente na forma de análise comparada das performances de grupo (classes, por exemplo) que tem seguido percursos formativos no âmbito da Mídia Educação e de grupos que não seguiram, para evidenciar a disparidade de competências alfabéticas (e por isso de autonomia crítica) de uns e de outros. 
Sem por isso apresar juízos que envolvem uma má avaliação das contribuições originais que ela produziu, a impressão que se tem é que para a Mídia Educação, na maior parte dos casos e pelo menos até hoje, a exigência de confiabilidade seja (foi) mais forte a respeito da necessidade de introduzir formas de controle experimental sobre a qualidade dos procedimentos e das metodologias. Em geral, a impressão é que na Mídia Educação ainda não está colocada seriamente a questão do método, ou seja, do que deve ser considerado cientificamente relevante em situações em que também haja uma discreta produção de atividades e de reflexão metasistemática. Impressão esta que deverá ser comprovada pela análise e que pode constituir uma linha-guia para o futuro: investir na pesquisa porque é através da pesquisa que o método pode ser destacado.

\section{Notas}

1 NT: neste texto optamos pelo uso do termo mídia como sinônimo de meios. Embora sua tradução não seja unânime, Mídia Educação é um termo que corresponde à educação para os meios em Portugal, éducation aux médias em francês, educación para los médios em espanhol e media education em inglês. $\mathrm{Na}$ tradição italiana o termo é o mesmo usado na língua inglesa, media education, e para se referir às mídias, media.

2 Sobre relação entre mídia e socialização, Morcellini (1997) constitui um válido ponto de partida. Conferir também Greco (2000) e Martelli (2001). Para uma clara e documentada apresentação deste âmbito de pesquisa, conferir Caronia (2001), Caron e Caronia (2000), Von Felitzen, (2000), Rivoltella (2001, 2006), Bertolini (1998, 2001).

3 Em relação a este olhar, conferir as pesquisas de monitoração e avaliação desenvolvidas pela Università di Bologna, a Albero Azzurro, e pela Università di Torino, a Melevisione (COGGI, 2000; FARNÉ; GHERARDI, 1994; FARNÉ, 1997).

4 Conferir, entre outros, Bernardinis (1978), Galliani (1988), Rivoltella (1998).

5 NT: o sentido do termo eficácia utilizado no texto diz respeito a um processo que melhor consegue os resultados esperados, ou seja, ao bom êxito no resultado da intervenção educativa. 
6 São testemunhas, metodologicamente, a atenção à micro-história e à virada interpretativa que afirma as técnicas etnográficas e, mais em geral, os métodos qualitativos na pesquisa sociológica (MOORES, 1993).

7 Entendimento mais amplo, portanto, que aquele da pedagogia dos meios.

\section{Referências}

BAZALGETTE, C. (Ed.). Primary media education: a curriculum statement. London: British Film Institute, 1989.

BERNARDINIS, M. Il linguaggio delle immagini: come educare il bambino a saper vedere. Milano: Fabbri, 1978.

BERTOLINI, P. (Ed.). Navigando nel cyberspazio. Milano: Rizzoli, 1998. BERTOLINI, P. (Ed.). I bambini giudici della TV. Milano: Guerini \& Associati, 2001.

BEVORT, E.; DESBANS, C. Éducation aux medias: une confrontation des recherches et des experiences. In: JACQUINOT, G. (Org.). Les jeunes et lês medias: perspectives de la recherche dans le monde. Paris: L'Harmattan, 2002.

BUCKINGHAM, D. La recherche sur les jeunes et les médias au Royaume-Uni. In: JACQUINOT, G. (Org.). Les jeunes et lês médias: perspectives de la recherche dans le monde. Paris: L'Harmattan, 2002.

CARON, A.; CARONIA, L. Parler de television, parler de soi: une étude sur la mise en disourse des pratiques médiatiques au foyer. Communication, Universitè Laval, Quebec, v. 20, n. 1, p. 123-154, 2000.

CARONIA, L. La socializzazione ai media: contesti, interazioni e pratiche educative. Milano: Guerini \& Associati, 2002.

CASETTI, F.; DI CHIO, F. Analisi del film. Milano: Bompiani, 1990.

COGGI, C. (Org.). Una TV per i bambini. Torino: Segalibro, 2000.

FARNÉ, R. L'albero azzurro nella prescuola: alcune note di ricerca. Ikon, Milano, v. 34, p. 109-145, 1997. 
FARNÉ, R.; GHERARDI, V. All'ombra di un albero azzurro. Bologna: CLUEB, 1994.

GALLIANI, L. Educazione ai linguaggi audiovisivi. Torino: SEI, 1988.

. Note introduttive: appunti per una vera storia dell'educazione ai media, con i media, attraverso i media. Studium Educationis, Trento, v. 3, p. 563-576, 2002.

GRECO, G. Socializzazione virtuale: bambini e TV nei nuovi scenari tecnologici. Soveria Mannelli: Rubettino, 2000.

JACQUINOT, G. Le scienze dell'educazione (SEd) e le Scienze dell'Informazione e della Comunicazione (SIC). Prospettive di un incontro. Intermed, Roma, v. 3, p. 4-7, 2000.

- Les jeunes et les médias: perspectives de la recherche dans le monde. Paris: L'Harmattan, 2002.

MARTELLI, S. Videosocializzazione: processi educativi e nuovi media. Milano: FrancoAngeli, 2001.

MESSINA, L. Media e apprendimento: il contributo della ricerca psicopedagogica. Studium Educations, Trento, v. 3, p. 593-615, 2002.

MOORES, S. Interpreting audiences: the etnography of media consumption. London: Thousand Oaks, 1993.

MORCELLINI, M. Passaggio al futuro: formazione e socializzazione tra vecchi e nuovi media. Milano: Il Saggiatore, 1997.

PESARE, F. La soggettività nella progettazione educativa. Roma: Carocci, 2002. RIVOLTELLA, P. C. (Org.). I rag@zzi delWeb. Milano: Vita e Pensiero, 2001.

. (Org.). L'audiovisivo e la formazione: metodi per l'analisi. Padova: CEDAM, 1998. - Media education: fondamenti didattici e prospettive di ricerca. Brescia: La Scuola, 2005. Media education: modelli, esperienze, profilo disciplinare. Roma: Carocci, 2001. 
RIVOLTELLA, P. C. Screen Generation. Milano: Vita e Pensiero, 2006.

SAGAYARAJ, D. Media education as addressed by the international congresses for communication within the period 1990-2000: key concepts, perspectives, difficulties and main paradigms. 2003. Tesi (Dottorato Scienze dell'Educazione) - Facoltá di Scienze dell'Educazione Roma: Università Pontificia Salesiana, 2003.

SILVERSTONE, R. Why study the media? London: Sage, 1999.

VAN DER MAREN, J. La recherche appliquée en pédagogie: Des Modèles pour l'enseignement. Bruxelles: de Boeck, 2003.

VARISCO, B. M. Costruttivismo socio-culturale. Roma: Carocci, 2003.

VON FELITZEN, C.; CARLSSON, U. (Org.). Children in the New Media Landscape. Goteborg: UNESCO/ International Clearing House Nordicom, 2000. 


\section{Media-Education and educational research}

\section{Abstract:}

This text proposes to define the specificity of research in the realm of Media Education in relation to educational research. To do so, it is based on the epistemological framework presented by Van der Maren (2003) contextualizing it in the interior of international research about the relationship between media and education.

Key words: Media. Educational Research. Epistemological. Education Auxiliary.

\section{Educación Mediática e investigación educativa}

\section{Resumen:}

En este texto se propone definir la especificidad de la investigación en el ámbito de la educación mediática dentro del contexto de la investigación educativa. Para tal fin, se parte de la perspectiva epistemológica presentada por Van der Maren (2003) contextualizándola en el interior de la investigación internacional, sobre la relación entre medios y educación.

Palabras-clave: Medios. Investigación educacional. Epistemología. Educación.

\section{Pier Cesare Rivoltella}

Cattolica del Sacro Cuore (UCSC), Milano

Tel. Uff. +39.02.72343038

Fax Uff. +39.02.72343040

Tel. ab. +39.0363 .302841$

E-mail: piercesare.rivoltella@unicatt.it

\section{Tradução Monica Fantin}

Doutora em Educação pelo PPGE/UFSC

Professora do Centro de Ciências de Educação

Universidade Federal de Santa Catarina (UFSC)

Rua Prof. Walter Bona Castelan, 434

Florianópolis, SC

Tel: 32332759/84121285

E-mail:mfantin@terra.com.br

Recebido em: 26/3/2009

Aprovado em: 30/5/2009 